Revista Digital Universitaria

Vol. 23, Núm. 1, enero-febrero 2022

\title{
Sistema abierto y letras hispánicas: el viaje a través de un agujero de conejo
}

\author{
Morgana Carranco
}

\section{Resumen}

En este testimonio se comparte la experiencia de cursar la Licenciatura en Lengua y Literaturas Hispánicas en el Sistema de Universidad Abierto y Educación a Distancia de la Universidad Nacional Autónoma de México. Se abordan las razones y motivaciones para estudiar una carrera en el sistema abierto, así como los aprendizajes a nivel personal y profesional.

Palabras clave: universidad abierta, letras hispánicas, segunda carrera, desarrollo profesional, testimonio.

\section{Open system and Hispanic literature: the joys down a RabBit hole}

\begin{abstract}
This testimony shares the experience of studying a Bachelor's Degree in Hispanic Language and Literatures in the Open University and Distance Education System of the National Autonomous University of Mexico (UNAM). It addresses the reasons and motivations for studying a degree in the open system, as well as the personal and professional learnings.
\end{abstract}

Keywords: open university, hispanic literature, second career, professional development, testimony. 
sentían que esa era la oportunidad de culminar la educación que habían deseado por años, o, como yo, de explorar temas que su alma anhelaba conocer.

Estaba aquella mujer que trabajaba en comunicación y publicidad, con empleo estable y bien remunerado, pero que llevaba mucho tiempo en talleres de literatura y creación y que tenía una pasión por la lingüística y la enseñanza de idiomas. Había un editor de muchos años que amaba leer y que quería seguir aprendiendo sobre su materia. Y aquel grupo de mujeres adultas mayores cuyo ímpetu y curiosidad eran contagiosos.

Y estaban ellos: mis mejores amigos. Él, una de las personas más inteligentes y cultas que conozco, trabajador y eficiente, padre joven, el primero de su familia en ir a la universidad. Aquel otro que había sido marino y artemarcialista antes de entrar a letras: idealista, leal y noble. El que escribía teatro y el que escribía cine. Aquél que también se dedicaba a los deportes y a su organización. Y la chica asalariada que estaba construyendo su negocio propio. En ningún otro lugar los hubiera conocido.

$\star \star \star$

La primera vez que escuché del Sistema de Universidad Abierto y Educación a Distancia (suAyed) de la Universidad Nacional Autónoma de México (UNAM), fue gracias a una de mis mejores amigas. Ella acababa de entrar a letras inglesas, y el hecho de que estuviera en otra carrera después de genómicas me pareció inspirador. La verdad era que ambas teníamos algunas dudas sobre si seguir con nuestro camino en la ciencia y compartíamos el mismo gusto por la literatura.

No es que no me haya gustado estudiar la Licenciatura en Ciencias Genómicas. De hecho, lo disfruté mucho. Era un ambiente intelectualmente estimulante y todo lo que aprendí era interesantísimo. Sin embargo, me encontraba haciendo la Maestría en Infección e Inmunidad en Holanda y no me veía trabajando en ello, quería algo diferente. No sé si fue la frialdad del clima y de la gente, las limitaciones económicas, el que extrañaba a mi familia, o el que la ciencia ya no me llenaba como antes, lo que me llevó a tomar refugio en la biblioteca de Rotterdam y reconectarme con la literatura y su magia.

Regresé a México y mientras seguía trabajando como bioinformática, ingresé a letras hispánicas. Elegí esta carrera porque cuando estuve en Holanda añoré pronunciar, sentir y expresarme en español. Y me di cuenta de que había muchas obras, personajes y autores en esta lengua que desconocía; en particular los de mi país. Quería explorarlos, experimentarlos, poseerlos. Escogí el Sistema de Universidad Abierta (SUA), al igual que muchos de mis compañeros, por su flexibilidad de horario, porque te permite cursar las materias al mismo tiempo que se sigue trabajando, estudiando otra carrera o atendiendo diversas actividades.

Letras hispánicas fue entrar a un agujero del conejo: lleno de temas, personas y objetos desconocidos, que capturaban del todo mi atención, y donde la lógica era muy diferente a la que teníamos en ciencias. Los sentimientos eran permitidos y exaltados, y las visiones propias y la subjetividad, fomentadas. 
Resultó que el sistema abierto funciona muy bien para mí, pues se parece a la manera en la que llevo a cabo las cosas: estoy acostumbrada a leer y a estudiar por mi cuenta y a organizar las actividades de acuerdo con el tiempo que dispongo, como mejor me convenga, según las circunstancias. No obstante, la interacción, retroalimentación y contacto humano me enriquecen.

Y es que estar en letras hispánicas en el sua no es sólo para formarse "en las áreas de la literatura española e hispanoamericana, lingüística, metodología de la investigación e iniciación profesional con una amplia visión de conjunto de las humanidades" (Acerca del departamento, s. f.). Personalmente, fue abrir mi perspectiva a otras formas y visiones de vida, a caminos muy distintos a los míos, a temas desconocidos y que en algún momento había considerado lejanos o no tan significativos. Se trató de ponerme en contacto con personas con las que difícilmente hubiera coincidido; aprender de ellas, de su contexto y motivaciones.

Letras hispánicas en el sua de la Facultad de Filosofía y Letras me cambió. Allí entendí que los sueños de la infancia no tienen que ser los mismos que los de la adultez. Que la vida es acerca de aprender: de los otros, de las circunstancias y de uno mismo. Alli fue la primera vez en muchos años que me sentí libre, como yo misma. Con la capacidad y motivación de explorar otros senderos que me había vedado. Fue donde pude reencontrarme y reinventarme, donde tomé la dirección que me trajo hasta aquí: a esta revista, a este texto. A explorar un sinfín de agujeros de conejo espectaculares.

\section{Referencias}

* Acerca del departamento. (s.f.). http://www.suafyl.filos.unam.mx/hispanicas_suayed/

\section{Sitios de interés}

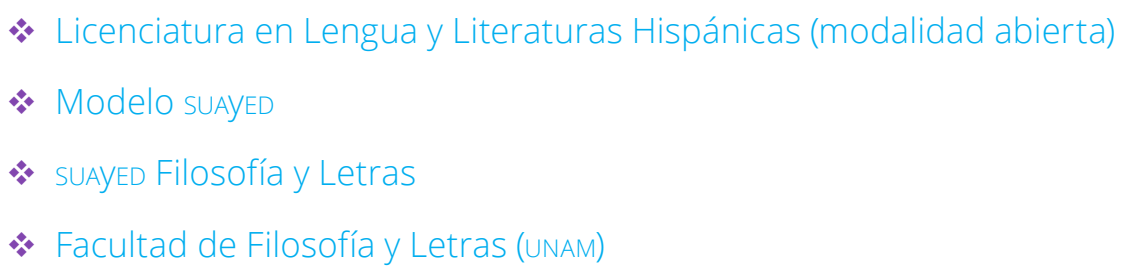

\section{Cómo CITAR ESTE ARTículo}

* Carranco, Morgana. (2022, enero-febrero). Sistema abierto y letras hispánicas: el viaje a través de un agujero de conejo. Revista Digital Universitaria (RDU), 23(1). http://doi.org/10.22201/cuaieed.16076079e.2022.23.1.12 